\title{
Challenges of Caregivers to Disclose their Children's HIV Positive Status Receiving Highly Active Anti Retroviral Therapy at Pediatric Anti Retroviral Therapy Clinics in Bahir Dar, North West Ethiopia
}

\section{Amare Alemu $^{1 *}$, Balcha Berhanu² and Solomon Emishaw ${ }^{1}$}

${ }^{1}$ Department of Nursing and Midwifery, College of Health Sciences, Mekelle University, Mekelle, Ethiopia

${ }^{2}$ Department of Nursing and Midwifery, School of Allied Health Sciences, College of Health Sciences, Addis Ababa University, Ethiopia

\begin{abstract}
Background: HIV infected children who started highly active antiretroviral therapy in antiretroviral therapy clinics have survived to older age, and disclosure has become an essential part of their care. Hence, this study tried to (a) estimate the prevalence of HIV disclosure among school-aged children in Bahir Dar, North West Ethiopia, and (b) assess caregivers' barriers to disclose their children's HIV positive status receiving highly active antiretroviral therapy in pediatric antiretroviral therapy clinics.
\end{abstract}

Methods: Institution based cross sectional study were conducted among 231 caregivers of pediatric antiretroviral therapy children on highly active antiretroviral therapy aged 6-14 years in four centres in Bahir Dar, North West Ethiopia. Caregivers were obtained proportionally and interviewed consecutively with convenience to respond for the structured pre-tested questionnaire. Data were entered into Epi Info version 3.5 and analyzed by using SPSS version 20 software for windows. Bivariate and multivariate logistic regression analyses were done.

Results: The prevalence of disclosure of children's HIV positive status on highly active antiretroviral therapy was $31.5 \%$. Religion of caregivers $(A O R=4.27[95 \% \mathrm{Cl}=1.24,14.73])$, family number $(\mathrm{AOR}=3.73[95 \% \mathrm{Cl}=1.11$, 12.48]), age of child $(\mathrm{AOR}=9.87$ [95\% $\mathrm{Cl}=3.47,28.07])$, child age when $\mathrm{ART}$ started $(\mathrm{AOR}=6.15[95 \% \mathrm{Cl}=1.76$, 21.50]), and children time on ART (AOR $=5.40[95 \% \mathrm{Cl}=1.87,15.55])$ were found to have statistically significant association with disclosure of HIV positive status to HIV infected children.

Conclusion: Addressing and scaling up efforts on stigma and discrimination in neighbourhood, communities, and school settings; and developing guideline for disclosure of children with HIVIAIDS in Ethiopian context will increase the rate of disclosure of children's HIV positive status on highly active antiretroviral therapy.

Keywords: Disclosure; HIV; Children; Caregivers; HAART; Ethiopia

\section{Introduction}

Children under 15 years of age account for approximately 3.4 million of the people living with human immune virus (HIV)/acquired immune deficiency syndrome (AIDS) worldwide, and almost $90 \%$ of all HIV infected children live in sub-Saharan Africa, including Ethiopia, according to the latest estimates from the Joint United Nations Programme on HIV/AIDS (UNAIDS) [1]. The exact prevalence of HIV in children is not known but, overall less than 1 percent of Ethiopian youth age 15 - 24 tested positive for HIV [2]. In late 2011, around 250,000 people were on antiretroviral therapy (ART) in Ethiopia [3]. There are currently about 135,000 children less than 14 years of age living with HIV/AIDS and from these, around 16,000 children are on treatment $[3,4]$. With the start of national programme for providing care and free highly active antiretroviral therapy (HAART) to children, there has been a significant reduction in morbidity and mortality of HIV infected children and more of them are surviving through childhood and into adolescence with improved quality of life [4]. Along with the increased survival of children infected with HIV, disclosure of HIV status to children remains a complex and a critical clinical issue in the care of HIV infected children [3]. World Health organization (WHO) and American Academy of Pediatrics (AAP) strongly encouraged disclosing HIV infection status to school aged children and younger children should be informed incrementally to accommodate their cognitive skills and emotional maturity $[5,6]$.

Telling children and adolescents about their HIV infection is a challenging dilemma because children are often asymptomatic in the early stages of HIV yet require daily medications and close monitoring [7]. Caregivers and healthcare workers are presented with group of challenges around disclosure, including deciding on what is in the child's best interest and when, why and how information about his/her HIV positive status should be shared with him/her. Caregivers are also reluctant to disclose the HIV positive status to their children for fear of social rejection and isolation, parental sense of guilt, and fear that the child would not keep diagnosis to themselves [8]. There is also a lot of controversy about what and when to tell children living with HIV about their diagnosis. The conflict and controversy arises because many families don't think their children can handle the information and they don't want to upset them because they've already been through so much [8]

However, several studies have documented the benefits of disclosure of the HIV positive status to HIV infected children; psychological

*Corresponding author: Amare Alemu, Department of Nursing and Midwifery, College of Health Sciences, Mekelle University, P.O.BOX 1871, Mekelle, Ethiopia, Tel: +251-034-440-6963; Fax: +251-034-441-66-81/40-93-04 E-mail: ame439@yahoo.com; semishaw@gmail.com

Received August 26, 2013; Accepted October 17, 2013; Published October 22 2013

Citation: Alemu A, Berhanu B, Emishaw S (2013) Challenges of Caregivers to Disclose their Children's HIV Positive Status Receiving Highly Active Ant Retroviral Therapy at Pediatric Anti Retroviral Therapy Clinics in Bahir Dar, North West Ethiopia. J AIDS Clin Res 4: 253. doi: 10.4172/2155-6113.1000253

Copyright: @ 2013 Alemu A, et al. This is an open-access article distributed under the terms of the Creative Commons Attribution License, which permits unrestricted use, distribution, and reproduction in any medium, provided the original author and source are credited. 
Citation: Alemu A, Berhanu B, Emishaw S (2013) Challenges of Caregivers to Disclose their Children's HIV Positive Status Receiving Highly Active Anti Retroviral Therapy at Pediatric Anti Retroviral Therapy Clinics in Bahir Dar, North West Ethiopia. J AIDS Clin Res 4: 253. doi: 10.4172/21556113.1000253

Page 2 of 7

benefits (facilitate children's adjustment), and positive effects on the clinical course of the disease (increase adherence to mediations, treatment regimens, doctor visits, and hospitalizations) [7]. Despite concerns about the social and psychological impacts of disclosure to children, some studies in industrialized nations show that HIV infected children fare well after disclosure, and even better when compared to children unaware of their HIV infection [9].

Since there is a significant advance in HIV treatment and care, and children continue to be born with HIV infection, disclosure of HIV infection to children remains a pertinent issue [10]. In addition, as children reach adolescence and begin risk taking behaviours, knowledge about their disease becomes essential for both personal health maintenance and HIV prevention within the larger population [4]. Data showed that when children had been on ART for some time, they no longer experienced symptoms evident in the illness and therefore did not understand why they should continue taking medication [11]. Pediatric HIV providers generally believe that disclosure is important for helping children understand the need for ART and for creating trusting relationships that facilitate adherence [10]. Thus this study assessed caregivers' barriers/factors on disclosure of their children's HIV positive status and determined the factors for caregivers associated with disclosure of HIV positive status in their children receiving HAART in Bahir Dar, North West Ethiopia.

\section{Methods}

\section{Study design, area and period}

An institution-based cross sectional study was conducted among caregivers of children aged 6 - 14 years who were on HAART using structured interviews. A total of 231 caregivers were recruited from four pediatric ART clinics in Bahir Dar, North West Ethiopia. Data were collected between March and May, 2013. At the time of data collection, the registration records indicated that about 560 children aged between 6 and 14 years were receiving HAART in these four centres. The centres provide services to children from surrounding rural villages and other nearby towns. Most of the children who were receiving HAART from these pediatric ART clinics were from their home town, Bahir Dar. Caregivers of pediatric ART children were recruited proportionally to the client flow from each pediatric ART clinics. For the purpose of this study, we defined a caregiver as the biological mother, biological father, grandmother, grandfather, foster parent, or other relatives who performs primary care giving functions for the child routinely or on a daily basis.

\section{Sampling}

The sample size was calculated using single population proportion formula with estimated proportion of disclosure among school-age (6 -14 years) children on HAART put at $16.3 \%$, a figure obtained from a published work by Abebe and Teferra [12]. Assuming a marginal error of $5 \%$ and a $10 \%$ non-respondent rate, the estimated sample size was 231 .

\section{Data collection}

Pre-tested structured questionnaire was prepared by reviewing previously done studies on the topic of disclosure of HIV to children [8,9,13-16]. The questionnaire was first prepared in English and then translated in to Amharic, the local language of the caregivers in the study area. The data were collected using structured intervieweradministered questionnaire. The questionnaires were administered to all caregivers of children aged 6 to 14 years who were attending the pediatric ART clinics during the data collection period, and who met the inclusion criteria. The interview took place while these caregivers waited for consultation and medication during the routine monthly visits for their children in the ART clinic. In addition, caregivers provided demographic information such as age, gender, school grade, age at diagnosis of HIV, duration of intake of ART and disclosure status of the children under their care. The questionnaire also contained openended questions. Caregivers of children who had not disclosed the HIV status of their children to their words was asked the main reasons why they have not disclosed this information.

\section{Data quality control}

Data were collected by four ART trained nurses who were responsible for in the follow up of children and worked in the ART units from each pediatric ART clinics after one day training was given about the objectives and procedures of the data collection by the investigators. Questionnaire was pre-tested at Felege Hiwot Referral Hospital to assess clarity, understand ability, flow and consistency, and revised prior to the start of data collection. Data completeness and consistency was checked by the investigators. Data cleaning and editing took place; missed values were statistically handled to help address concerns.

\section{Data analysis}

Data were entered using Epi Info version 3.5 and exported to, and then analyzed using SPSS version 20 . First, descriptive statistics were carried out to explore the socio-demographic characteristics of caregivers and children, and the results were summarised as frequencies and percentages between children who knew their HIV diagnosis and those who did not know. To determine which factors were associated with HIV positive status disclosure to infected children, binary and multiple logistic regressions were employed. Variables associated with disclosure in bivariate analyses were included in the multiple logistic models and P-values less than 0.05 were considered to be statistically significant in all cases.

\section{Ethical consideration}

Ethical approval and clearance was taken from institutional review board of College of Health Sciences, Addis Ababa University. The Regional Health Bureau gave permission to conduct the study in each pediatric ART clinics in the study area. After the purpose of the study was explained, a written informed consent was obtained from caregivers before data collection. Caregivers were informed that participating in the study was voluntary and that refusal to participate would not compromise the medical care their children received from the pediatric ART clinics. The right to withdraw from the study at any time was also assured. The interviews were conducted in a private room in the pediatric ART clinics to ensure privacy. Coding was used to eliminate names and other personal identification of respondents throughout the study process to ensure participants confidentiality.

\section{Results}

\section{Caregivers' demographic characteristics}

A total of 231 caregivers of children aged 6 - 14 years on HAART provided information on the children under their care. Three-quarters, 173 (75\%) of caregivers lived in their home town, Bahir Dar. The main caregivers were biological parents $188(81.4 \%)$, followed by related relatives $29(12.6 \%)$, and $14(6.1 \%)$ were orphaned children. About $82(35.5 \%)$ of the caregivers had primary school education and $29.9 \%$ had never attended any school. Half, $116(50.2 \%)$ of the caregivers were married and more than half 148 (64.1\%) were unemployed. In 
Citation: Alemu A, Berhanu B, Emishaw S (2013) Challenges of Caregivers to Disclose their Children's HIV Positive Status Receiving Highly Active Anti Retroviral Therapy at Pediatric Anti Retroviral Therapy Clinics in Bahir Dar, North West Ethiopia. J AIDS Clin Res 4: 253. doi: 10.4172/21556113.1000253

Page 3 of 7

addition, data were collected on the caregivers' HIV status, and about $189(81.8 \%)$ of the caregivers were lived with the HIV virus and 42 (18.2\%) were HIV negative (Table 1).

\section{Children's demographic characteristics}

Of 231 children ages 6 - 14 years, there were nearly equal numbers of girls $116(50.2 \%)$ and boys $115(49.8 \%)$ in the sample. The mean age of the children was 9.8 years, $(\mathrm{SD}=2.6$, range $6-14$ years). Almost half, 120 (51.9\%) children were between 10 - 14 years of age while the

\begin{tabular}{|c|c|c|c|c|c|c|c|}
\hline \multirow{3}{*}{\begin{tabular}{|l|} 
Variables \\
Address \\
\end{tabular}} & \multirow[t]{3}{*}{ Frequency } & \multirow[t]{3}{*}{ Percent } & \multicolumn{5}{|c|}{ Disclosure status $(\mathrm{N}=231)$} \\
\hline & & & \multicolumn{2}{|c|}{ Yes $(n=81)$} & \multicolumn{3}{|c|}{ No $(n=150)$} \\
\hline & & & $\mathrm{n}$ & $\%$ & $\mathrm{n}$ & $\%$ & \\
\hline & Bahir Dar & 173 & 74.9 & 70 & 40.5 & 103 & 59.5 \\
\hline & Outside Bahir Dar* & 58 & 25.1 & 11 & 19.0 & 47 & 81.0 \\
\hline \multicolumn{8}{|c|}{ Residence } \\
\hline & Urban & 205 & 88.7 & 78 & 38.0 & 127 & 62.0 \\
\hline & Rural & 26 & 11.3 & 3 & 11.5 & 23 & 88.5 \\
\hline \multicolumn{8}{|l|}{ Ethnicity } \\
\hline & Amhara & 228 & 98.7 & 80 & 35.1 & 148 & 64.9 \\
\hline & Others $^{\star *}$ & 3 & 1.3 & 1 & 33.3 & 2 & 66.7 \\
\hline \multicolumn{8}{|l|}{ Religion } \\
\hline & Orthodox & 196 & 84.8 & 74 & 37.8 & 122 & 62.2 \\
\hline & Others ${ }^{\star \star \star}$ & 35 & 15.2 & 7 & 20.0 & 28 & 80.0 \\
\hline \multicolumn{8}{|c|}{ Educational status } \\
\hline & $\begin{array}{l}\text { Unable to read } \\
\text { and write }\end{array}$ & 69 & 29.9 & 16 & 23.2 & 53 & 76.8 \\
\hline & Primary (1-8) & 82 & 35.5 & 34 & 41.5 & 48 & 58.5 \\
\hline & Secondary $(9-12)$ & 46 & 19.9 & 17 & 37.0 & 29 & 63.0 \\
\hline & $\begin{array}{l}\text { Tertiary (Diploma } \\
\text { and above) }\end{array}$ & 34 & 14.7 & 14 & 41.2 & 20 & 58.8 \\
\hline \multicolumn{8}{|c|}{ Marital status } \\
\hline & Single & 31 & 13.4 & 15 & 48.4 & 16 & 51.6 \\
\hline & Married & 116 & 50.2 & 30 & 25.9 & 86 & 74.1 \\
\hline & Divorced & 41 & 17.7 & 16 & 39.0 & 25 & 61.0 \\
\hline & Widowed & 43 & 18.6 & 20 & 46.5 & 23 & 53.5 \\
\hline \multicolumn{8}{|c|}{ Occupation } \\
\hline & Farmer & 26 & 11.3 & 3 & 11.5 & 2334 & 88.5 \\
\hline & Employed & 57 & 24.7 & 23 & 40.4 & & 59.6 \\
\hline$t$ & Unemployed & 148 & 64.1 & 55 & 37.2 & 93 & 62.8 \\
\hline \multicolumn{8}{|c|}{ Monthly income (in ETB) } \\
\hline & $<500$ & 125 & 54.1 & 38 & 30.4 & 87 & 69.6 \\
\hline & $500-1000$ & 56 & 24.2 & 25 & 44.6 & 31 & 55.4 \\
\hline & $1001-2000$ & 33 & 14.3 & 12 & 36.4 & 21 & 63.6 \\
\hline & $>2000$ & 17 & 7.4 & 6 & 35.3 & 11 & 64.7 \\
\hline \multicolumn{8}{|l|}{ Relation } \\
\hline & $\begin{array}{l}\text { Parents (Biologi- } \\
\text { cal) }\end{array}$ & 188 & 81.4 & 56 & 29.8 & 132 & 70.2 \\
\hline & Related relatives & 29 & 12.6 & 16 & 55.2 & 13 & 44.8 \\
\hline & Orphaned children & 14 & 6.1 & 9 & 64.3 & 5 & 35.7 \\
\hline \multicolumn{8}{|c|}{ Family number } \\
\hline & $<3$ & 207 & 89.6 & 67 & 32.4 & 140 & 67.6 \\
\hline & $>3$ & 24 & 10.4 & 14 & 58.3 & 10 & 41.7 \\
\hline \multicolumn{8}{|l|}{ HIV status } \\
\hline & Negative & 42 & 18.2 & 23 & 54.8 & 19 & 45.2 \\
\hline & Positive & 189 & 81.8 & 58 & 30.7 & 131 & 69.3 \\
\hline
\end{tabular}

*Gondar, Dangla, Merawi, Zegie, and others

** Tigray

*** Muslim and Protestant

ETB: Ethiopian Birr

Table 1: Caregivers socio-demographic characteristics of HIV positive status disclosed and non disclosed school-age children at pediatric ART clinics in Bahir Dar, North West Ethiopia, $2013(n=231)$.

\begin{tabular}{|c|c|c|c|c|c|c|}
\hline \multirow{3}{*}{ Variables } & \multirow{3}{*}{ Frequency } & \multirow{3}{*}{ Percent } & \multicolumn{4}{|c|}{ Disclosure status $(\mathrm{N}=231)$} \\
\hline & & & \multicolumn{4}{|c|}{ Yes $(n=81) \quad$ No $(n=150)$} \\
\hline & & & $n$ & $\%$ & $n$ & $\%$ \\
\hline \multicolumn{7}{|l|}{ Age } \\
\hline $6-9$ years & 111 & 48.1 & 9 & 8.1 & 102 & 91.9 \\
\hline $10-14$ years & 120 & 51.9 & 27 & 60.0 & 48 & 40.0 \\
\hline \multicolumn{7}{|l|}{ Sex } \\
\hline Boy & 115 & 49.8 & 42 & 36.5 & 73 & 63.5 \\
\hline Girl & 116 & 50.2 & 39 & 33.6 & 77 & 66.4 \\
\hline \multicolumn{7}{|c|}{ Age at diagnosis of HIV } \\
\hline $1-5$ years & 149 & 64.5 & 37 & 24.8 & 112 & 75.2 \\
\hline $6-11$ years & 82 & 35.5 & 44 & 53.7 & 38 & 46.3 \\
\hline \multicolumn{7}{|c|}{ WHO clinical staging } \\
\hline I & 54 & 23.4 & 24 & 44.4 & 30 & 55.6 \\
\hline II & 52 & 22.5 & 16 & 30.8 & 36 & 69.2 \\
\hline III & 114 & 49.4 & 37 & 32.5 & 77 & 67.5 \\
\hline IV & 11 & 4.8 & 4 & 36.4 & 7 & 63.6 \\
\hline \multicolumn{7}{|c|}{ Age when ART was initiated } \\
\hline $1-5$ years & 123 & 53.2 & 23 & 18.7 & 100 & 81.3 \\
\hline $6-11$ years & 108 & 46.8 & 58 & 53.7 & 50 & 46.3 \\
\hline \multicolumn{7}{|c|}{ Duration on ART } \\
\hline $1-5$ years & 176 & 76.2 & 48 & 27.3 & 128 & 72.7 \\
\hline $6-12$ years & 55 & 23.8 & 33 & 60.0 & 22 & 40.0 \\
\hline \multicolumn{7}{|l|}{ Schooling } \\
\hline Yes & 209 & 90.5 & 80 & 38.3 & 129 & 61.7 \\
\hline No & 22 & 9.5 & 1 & 4.5 & 21 & 95.5 \\
\hline
\end{tabular}

*Gondar, Dangla, Merawi, Zegie, and others

** Tigray

*** Muslim and Protestant

ETB: Ethiopian Birr

Table 2: Disclosure status of children on HAART in pediatric ART clinics by demographic and clinic characteristics in Bahir Dar, Ethiopia, $2013(n=231)$.

rest $111(48.1 \%)$ were between 6 - 9 years. All the caregivers provided information on age at diagnosis of HIV; the majority 149 (64.5\%) were diagnosed between 1-5 years and about one third 82 (35.5\%) were diagnosed between 6 to 11 years. The mean age at diagnosis was 4.8 years $(\mathrm{SD}=2.5)$. All $(100 \%)$ of the children were on HAART; the mean time on ART was 4.0 years ( $\mathrm{SD}=2.1)$, and the mean age when children started ART was 5.7 years $(\mathrm{SD}=2.4)$. The majority of the children 209 (90.5\%) were attending school (Table 2).

\section{Prevalence of children's HIV positive status}

Based on caregivers reports, 81 (35.1\%) of the children knew about their positive HIV status.

Of the children who didn't know their HIV positive status, more than two third $131(87.33 \%)$ were reportedly told other related diagnosis like TB, Pneumonia and others, and the rest 19 (12.67) didn't know at all about their illness. Caregivers who had not informed their children about their HIV diagnosis $(n=150)$ responded question about their responses for their children's repeated hospital visit and daily ART taking, and about 67 (44.7\%) of them replied their reasons for associated physical illness while $36(24 \%)$ of them said that for routine health check up and improving child's health. About 47 (31.3\%) caregivers didn't communicate on this information.

\section{Preferred age of children's HIV positive disclosure}

Caregivers were asked the appropriate time for children's HIV positive status disclosure, and almost half $116(50.2 \%)$ replied from 10 - 14 years, 73 (31.6\%) 15 years and above and only 17 (7.4\%) caregivers didn't know the preferred age for disclosure (Figure 1). Caregivers were 
Citation: Alemu A, Berhanu B, Emishaw S (2013) Challenges of Caregivers to Disclose their Children's HIV Positive Status Receiving Highly Active Anti Retroviral Therapy at Pediatric Anti Retroviral Therapy Clinics in Bahir Dar, North West Ethiopia. J AIDS Clin Res 4: 253. doi: 10.4172/21556113.1000253

Page 4 of 7

also asked about the person who should be the person responsible for disclosure of HIV status to children, and about 99 (43\%) of them replied health care providers (doctors, nurses and counsellors), and 89 (39\%) family (father/mother).

\section{Caregivers' reasons for non-disclosure their children's HIV positive status}

Caregivers who had not informed their children about their HIV diagnosis $(\mathrm{n}=150)$ also responded to a question about their reasons for not disclosing. About 67 (44.4\%) of them replied they would be socially rejected (fear of stigma and discrimination); 64 (42.7\%) delayed disclosure for fear of negative consequences for the child and caregivers believed that disclosure would stress, hurt and worry the child (fear of emotional distress); 61 (40.7\%) of the caregivers believed that their child was too young to understand the HIV diagnosis. Lastly about $34.0 \%$ of caregivers delayed disclosure because they believed that they did not know how to tell or how to approach the disclosure of the HIV diagnosis to their children (lack of knowledge and skill) (Figure 2).

\section{Challenges and barriers associated with children's HIV positive status disclosure}

Bivariate analysis in the binary logistic regression model showed that residence of caregivers was significantly associated with disclosure status to children with caregivers living in urban areas were about 5 times more likely to disclose the HIV status to the children when

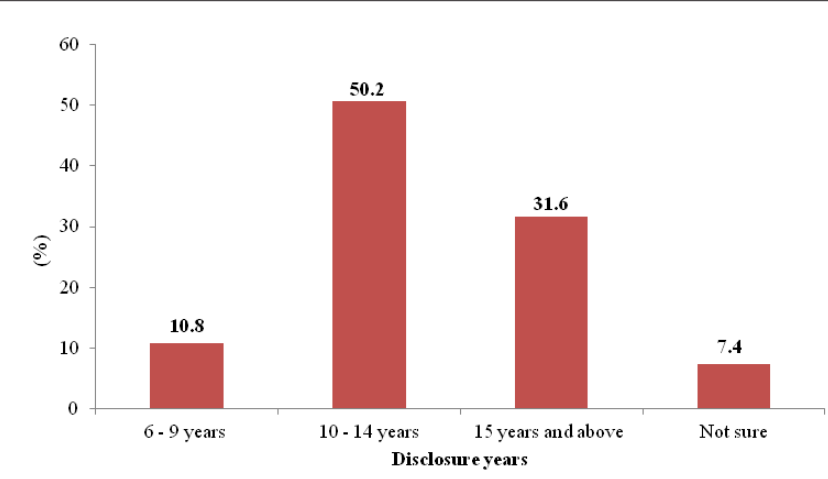

Figure 1: Caregivers' response on the preferred age for their children's HIV positive status disclosure in pediatric ART clinics, Bahir Dar, North West Ethiopia, 2013

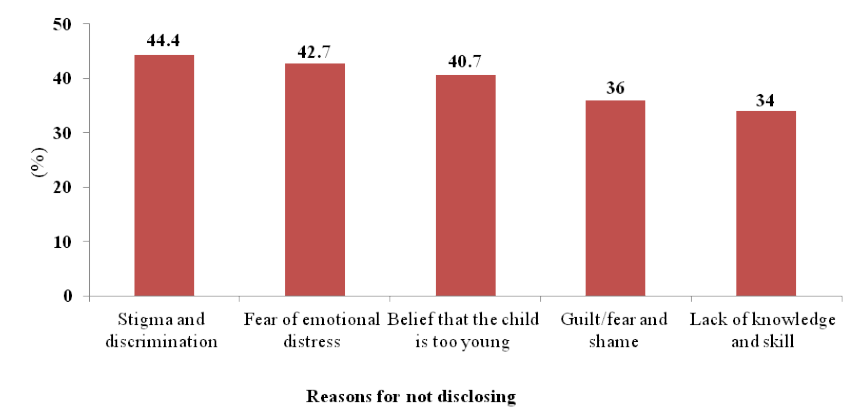

Some caregivers gave multiple responses on the reasons for not disclosing their children's HIV positive status; therefore the numbers reported are more than the total $(n=150)$

Figure 2: Caregivers' reasons for not disclosing their children's HIV positive status in pediatric ART clinics, Bahir Dar, North West Ethiopia, 2013. compared to caregivers living in the rural areas (COR $=4.71[95 \% \mathrm{CI}$ $=1.37,16.20])$. Caregivers who were employed were 5.2 times more likely to disclose than those who didn't (COR $=5.19[95 \% \mathrm{CI}=1.39$, 19.30]). Non biological parents were 4.2 times more likely to disclose HIV positive status to HIV infected children as compared to biological ones $(\mathrm{COR}=4.24[95 \% \mathrm{CI}=1.36,13.23])$. Address and HIV status of caregivers were associated with children HIV positive status disclosure; caregivers who lived in Bahir Dar were 2.9 times more likely to disclose their children HIV status than those who lived outside Bahir Dar (COR $=2.90[95 \% \mathrm{CI}=1.40,5.98])$; similarly those caregivers who didn't live with the virus were 2.7 times more likely to disclose their children's HIV status as compared to those who did (COR $=2.73[95 \% \mathrm{CI}=1.38$, 5.40]). Likewise age at diagnosis and duration of ART were associated with disclosure status of children's HIV positive status; children whose diagnosis age 6 - 11 years were 3.5 times more likely to disclose than age $1-5$ years $(\mathrm{COR}=3.50[95 \% \mathrm{CI}=1.98,6.21])$; and those children who had taken ART for 6 - 12 years were 4 times more likely to disclose their HIV positive status as compared to those children who had taken ART for less than six years $(\mathrm{COR}=4.00[95 \% \mathrm{CI}=2.12,7.53])$. There was also a difference with regard to schooling status of children; children attended school were 13 times more likely to disclose their HIV positive status as compared to their counterpart $(\mathrm{COR}=13.02[95 \% \mathrm{CI}=1.72$, 98.71]) (Table 3).

As clearly showed on the multivariate logistic regression, five characteristics were independently and significantly associated with disclosure of HIV positive status to HIV infected children; religion $(\mathrm{AOR}=4.27[95 \% \mathrm{CI}=1.24,14.73])$, family number $(\mathrm{AOR}=3.73[95 \%$ $\mathrm{CI}=1.11,12.48])$, age of the child $(\mathrm{AOR}=9.87[95 \% \mathrm{CI}=3.47,28.07])$, age when ART was initiated $(\mathrm{AOR}=6.15[95 \% \mathrm{CI}=1.76,21.50])$ and duration on $\mathrm{ART}(\mathrm{AOR}=5.40[95 \% \mathrm{CI}=1.87,15.55])$. However, factors related to the caregiver such as marital status, occupation, relation with the child, and HIV positive status, as well as child's HIV diagnosis age, and schooling status of children were not significantly associated with disclosure of HIV positive status to HIV infected children in this study. Likewise caregiver's address and residence were not retained as a significant factor in the multivariate analysis (Table 3).

\section{Discussion}

This study determined the prevalence and barriers to disclose children's HIV positive status receiving HAART among caregivers of children aged 6 - 14 years in four pediatric ART clinics, Bahir Dar, North West Ethiopia. The prevalence of disclosure amongst caregivers' of children on HAART in this study was $31.5 \%$. This finding is low as compared to studies done in high-income countries in which the disclosure rate ranges from 25 to 70 percent in the USA and Canada, and 75 to 82 percent in Europe [9]. The lower prevalence of disclosure in this study as compared to developed countries might be due to caregivers' fear of stigma and discrimination and believed that their children would be isolated by their friends at school and in the community, and fear of negative consequences for the child. Caregivers were also lack knowledge and skills on how to approach/inform their HIV infected children about their HIV diagnosis in this study. On the other hand, in developed countries such as the USA, there are guidelines for disclosure of HIV positive status to children developed by the American Academy of Pediatrics [6] which contains detailed instructions on the process of disclosure but such guidelines do not exist in Ethiopia, although there was an effort of include issues related to disclosure in the "Guidelines for Pediatric HIV/AIDS Care in Ethiopia" developed by the Federal HIV/AIDS Prevention and Control Office and Federal Ministry of Health in 2008. However, the disclosure rate of children's HIV positive 
Citation: Alemu A, Berhanu B, Emishaw S (2013) Challenges of Caregivers to Disclose their Children's HIV Positive Status Receiving Highly Active Anti Retroviral Therapy at Pediatric Anti Retroviral Therapy Clinics in Bahir Dar, North West Ethiopia. J AIDS Clin Res 4: 253. doi: 10.4172/21556113.1000253

Page 5 of 7

\begin{tabular}{|c|c|c|c|c|c|c|c|c|}
\hline \multirow{3}{*}{ Variables } & \multicolumn{4}{|c|}{ Disclosure status $(\mathrm{N}=231)$} & \multirow[b]{3}{*}{ COR $(95 \% \mathrm{Cl})$} & \multirow[b]{3}{*}{ P-Value } & \multirow[b]{3}{*}{ AOR $(95 \% \mathrm{Cl})$} & \multirow[b]{3}{*}{ P-Value } \\
\hline & \multicolumn{2}{|c|}{ Yes $(n=81)$} & \multicolumn{2}{|c|}{ No $(n=150)$} & & & & \\
\hline & $\mathrm{n}$ & $\%$ & $\mathbf{n}$ & $\%$ & & & & \\
\hline \multicolumn{9}{|l|}{$\begin{array}{l}\text { Caregivers' variables } \\
\text { Address }\end{array}$} \\
\hline Bahir Dar & 70 & 40.5 & 103 & 59.5 & $2.90(1.40,5.98)$ & 0.004 & $1.42(0.44,4.64)$ & 0.557 \\
\hline Outside Bahir Dar* & 11 & 19.0 & 47 & 81.0 & 1.00 & & 1.00 & \\
\hline \multicolumn{9}{|l|}{ Residence } \\
\hline Urban & 78 & 38.0 & 127 & 62.0 & $4.71(1.37,16.20)$ & 0.014 & $5.40(0.00,14.45)$ & 0.879 \\
\hline Rural & 3 & 11.5 & 23 & 88.5 & 1.00 & & 1.00 & \\
\hline \multicolumn{9}{|l|}{ Religion } \\
\hline Orthodox & 74 & 37.8 & 122 & 62.2 & $2.42(1.01,5.83)$ & 0.048 & $4.27(1.24,14.73)$ & 0.021 \\
\hline Others ** & 7 & 20.0 & 28 & 80.0 & 1.00 & & 1.00 & \\
\hline \multicolumn{9}{|l|}{ Marital status } \\
\hline Single & 15 & 48.4 & 16 & 51.67 & $2.67(1.19,6.09)$ & 0.018 & $1.15(0.36,3.66)$ & 0.811 \\
\hline Married & & & 86 & 4.1 & $1.46(0.57,3.76)$ & & $0.48(0.12,1.83)$ & \\
\hline $\begin{array}{l}\text { Divorced } \\
\text { Widowed }\end{array}$ & $\begin{array}{l}30 \\
16 \\
20\end{array}$ & $\begin{array}{l}25.9 \\
39.0 \\
46.5\end{array}$ & $\begin{array}{l}25 \\
23\end{array}$ & $\begin{array}{l}61.0 \\
53.5\end{array}$ & $\begin{array}{c}1.08(0.43,2.71) \\
1.00\end{array}$ & & $\begin{array}{c}0.21(0.05,0.81) \\
1.00\end{array}$ & \\
\hline \multicolumn{9}{|l|}{ Occupation } \\
\hline Farmer & 3 & 11.5 & 23 & 88.5 & 1.00 & & 1.00 & \\
\hline $\begin{array}{l}\text { Employed } \\
\text { Unemployed }\end{array}$ & $\begin{array}{l}23 \\
55\end{array}$ & $\begin{array}{l}40.4 \\
37.2\end{array}$ & $\begin{array}{l}34 \\
93\end{array}$ & $\begin{array}{l}59.6 \\
62.8\end{array}$ & $\begin{array}{c}5.19(1.39,19.30) \\
1.14(0.61,2.14)\end{array}$ & 0.014 & $\begin{array}{l}1.72(0.00,4.45) \\
1.69(0.69,4.18)\end{array}$ & 0.961 \\
\hline $\begin{array}{l}\text { Relation } \\
\text { Parents (Biological) } \\
\text { Related relatives } \\
\text { Orphaned children }\end{array}$ & $\begin{array}{c}56 \\
16 \\
9\end{array}$ & $\begin{array}{l}29.8 \\
55.2 \\
64.3\end{array}$ & $\begin{array}{c}132 \\
13 \\
5\end{array}$ & $\begin{array}{l}70.2 \\
44.8 \\
35.7\end{array}$ & $\begin{array}{c}1.00 \\
1.46(0.39,5.45) \\
4.24(1.36,13.23)\end{array}$ & 0.013 & $\begin{array}{c}1.00 \\
4.32(0.77,24.13) \\
1.98(0.41,9.61)\end{array}$ & 0.397 \\
\hline $\begin{array}{c}\text { Family number } \\
\begin{array}{r}\leq 3 \\
>3\end{array}\end{array}$ & $\begin{array}{l}67 \\
14\end{array}$ & $\begin{array}{l}32.4 \\
58.3\end{array}$ & $\begin{array}{c}140 \\
10\end{array}$ & $\begin{array}{l}67.6 \\
41.7\end{array}$ & $\begin{array}{c}1.00 \\
2.92(1.23,6.93)\end{array}$ & 0.015 & $\begin{array}{c}1.00 \\
\mathbf{3 . 7 3}(1.11,12.48)\end{array}$ & 0.033 \\
\hline $\begin{array}{l}\text { HIV status } \\
\text { Negative } \\
\text { Positive }\end{array}$ & $\begin{array}{l}23 \\
58\end{array}$ & $\begin{array}{l}54.8 \\
30.7\end{array}$ & $\begin{array}{c}19 \\
131\end{array}$ & $\begin{array}{l}45.2 \\
69.3\end{array}$ & $\begin{array}{c}2.73(1.38,5.40) \\
1.00\end{array}$ & 0.004 & $\begin{array}{c}2.68(0.67,11.13) \\
1.00\end{array}$ & 0.174 \\
\hline $\begin{array}{l}\text { Children's variables } \\
\text { Age } \\
\qquad \begin{array}{l}6-9 \text { years } \\
10-14 \text { years }\end{array}\end{array}$ & $\begin{array}{c}9 \\
27\end{array}$ & $\begin{array}{c}8.1 \\
60.0\end{array}$ & $\begin{array}{c}102 \\
48\end{array}$ & $\begin{array}{l}91.9 \\
40.0\end{array}$ & $\begin{array}{c}1.00 \\
17.0(7.85,36.84)\end{array}$ & 0.00 & $\begin{array}{c}1.00 \\
9.87(3.47,28.07)\end{array}$ & 0.000 \\
\hline $\begin{array}{l}\text { Age at diagnosis of HIV } \\
1-5 \text { years } \\
\qquad 6-11 \text { years }\end{array}$ & $\begin{array}{l}37 \\
44\end{array}$ & $\begin{array}{l}24.8 \\
53.7\end{array}$ & $\begin{array}{c}112 \\
38\end{array}$ & $\begin{array}{l}75.2 \\
46.3\end{array}$ & $\begin{array}{c}1.00 \\
3.50(1.98,6.21)\end{array}$ & 0.000 & $\begin{array}{c}1.00 \\
0.32(0.10,1.03)\end{array}$ & 0.056 \\
\hline $\begin{array}{c}\text { Age when ART was initia } \\
\qquad \begin{array}{c}1-5 \text { years } \\
6-11 \text { years }\end{array}\end{array}$ & $\begin{array}{l}23 \\
58\end{array}$ & $\begin{array}{l}18.7 \\
53.7\end{array}$ & $\begin{array}{c}100 \\
50\end{array}$ & $\begin{array}{l}81.3 \\
46.3\end{array}$ & $\begin{array}{c}1.00 \\
5.04(2.79,9.10)\end{array}$ & 0.000 & $\begin{array}{c}1.00 \\
\mathbf{6 . 1 5}(1.76,21.50)\end{array}$ & 0.004 \\
\hline $\begin{array}{l}\text { Duration on ART } \\
\qquad \begin{array}{r}1-5 \text { years } \\
6-12 \text { years }\end{array}\end{array}$ & $\begin{array}{l}48 \\
33\end{array}$ & $\begin{array}{l}27.3 \\
60.0\end{array}$ & $\begin{array}{c}128 \\
22\end{array}$ & $\begin{array}{l}72.7 \\
40.0\end{array}$ & $\begin{array}{c}1.00 \\
4.00(2.12,7.53)\end{array}$ & 0.000 & $\begin{array}{c}1.00 \\
\mathbf{5 . 4 0}(1.87,15.55)\end{array}$ & 0.002 \\
\hline $\begin{array}{r}\text { Schooling } \\
\text { Yes } \\
\text { No }\end{array}$ & $\begin{array}{c}80 \\
1\end{array}$ & $\begin{array}{l}38.3 \\
4.5\end{array}$ & $\begin{array}{c}129 \\
21\end{array}$ & $\begin{array}{l}61.7 \\
95.5\end{array}$ & $\begin{array}{c}13.02(1.72,98.71) \\
1.00\end{array}$ & 0.013 & $\begin{array}{c}4.45(0.21,95.67) \\
1.00\end{array}$ & 0.341 \\
\hline
\end{tabular}

${ }^{*}$ Gondar, Dangla, Merawi, Zegie, and others

**Muslim and Protestant

COR - crude odds ratio $\quad \mathrm{AOR}$ - adjusted odds ratio $\quad \mathrm{Cl}$ - confidence interval

Table 3: Bivariate and multivariate analysis of challenges and factors of caregivers preventing disclosure of HIV positive status to heir HIV infected children in pediatric ART clinics, Bahir Dar, North West Ethiopia, 2013.

status receiving HAART in this study was better when compared to the study conducted from developing countries including Ethiopia, ranged from $20 \%$ to $30 \%$ in Ghana and South Africa [9,13,14,17], and $10 \%$ to $18 \%$ in Addis Ababa, Ethiopia $[8,12,18]$. The better prevalence rate (35.1\%) of disclosure in this study could possibly be explained to the increased number of older children (mean age of 9.8 years, range 6 - 14 years) enrolled for HAART.
In this study, caregivers' knowledge on the appropriate time for children's HIV positive status disclosure was 50.2\% agreed from 10 - 14 years and $32 \% 15$ years and above. This finding is in agreement with study done in South Africa more than $50 \%$ which ranged from $11-17$ years $[13,17]$. The reason for this might be caregivers' belief on their children age as being too young for disclosure so that this can hinder them from disclosing their children's HIV positive status. When 
Citation: Alemu A, Berhanu B, Emishaw S (2013) Challenges of Caregivers to Disclose their Children's HIV Positive Status Receiving Highly Active Anti Retroviral Therapy at Pediatric Anti Retroviral Therapy Clinics in Bahir Dar, North West Ethiopia. J AIDS Clin Res 4: 253. doi: 10.4172/21556113.1000253

Page 6 of 7

caregivers asked about the person who should be the person responsible for disclosure of HIV status to children in this study, about $60 \%$ of them replied health care providers and more than 55\% family (father/ mother). This result is consistent with the study conducted in Addis Ababa, Ethiopia $60 \%$ believed that the doctor should be responsible [8], and in South Africa $55 \%$ who thought that the biological mother should be the one to disclose the HIV diagnosis to the child [13].

In this study, from caregivers who had not informed their children about their HIV diagnosis about $45 \%$ of them put their reasons for not disclosed their children's HIV positive status because they would be socially rejected; more than $40 \%$ delayed disclosure for fear of negative consequences and emotional distress for the child; $40 \%$ of the caregivers believed that their child was too young to understand the HIV diagnosis, and about $34 \%$ of caregivers delayed disclosure because they lack knowledge and skill. This result is the same as indicated in South Africa, Ghana and Uganda included the child's too young age; the child would be socially rejected; fear of negative consequences for the child; and caregivers do not know how to tell or approach disclosure [9,13-17,19-24].

In our study, caregivers' religious engagement (religious beliefs) is associated with disclosure of children HIV positive status; Orthodox Christians were 4 times to disclose their children HIV positive status relative to their counterparts with other religion (AOR $=4.27[95 \%$ $\mathrm{CI}=1.24,14.73]$ ). This is consistent with the study indicated in Togo, West Africa [16]. This result could be explained that because majority of caregivers in this study were Orthodox Christian and household members believed that their children obtained absolute healing from God; this made them to be discussed with their children about HIV/ AIDS and their distress regarding HIV/AIDS could be decrease and finally this leads to inform to their children as they lived with the virus. Family number is also closely associated with disclosure; those children who lived with more than three family members were 3.7 times more likely to be disclosed their HIV positive status as compared to their counterparts $(\mathrm{AOR}=3.73[95 \% \mathrm{CI}=1.11,12.48]$ ). This finding is in conformity with the result in Uganda [25] where children lived with three or more families were more likely to be disclosed than their counterparts but it contradicts with the finding in Ghana [14] where the number of family lived with children had no association with disclosure. This difference could be explained that in the current study majority of children were between the age of 10 and 14 years, and $90 \%$ of them were attending school so that they ask a lot of questions and discuss with their families related to their illness.

Age of child was found to be a significant predictor of disclosure of HIV positive status; children 10 - 14 years of age were 9.9 times more likely to be disclosed/informed of their HIV positive status as compared to their counterparts $(\mathrm{AOR}=9.87[95 \% \mathrm{CI}=3.47,28.07])$. This result is consistent with the finding from developing countries including Ethiopia $[9,13,20-22]$ where children of the same age were significantly more likely to be disclosed than children 6 - 9 years of age, and this showed that older age of infected children as a determinant factor for HIV positive status disclosure. Likewise it is congruent with the study conducted in South Africa which showed the mean age at disclosure was 9.3 years [13] which was comparable with in the current study $(9.8$ years). This difference by age group could be explained that children of 10 - 14 age groups were more persistent in questioning the reasons as to why they were taking medication and majority of them were on schooling that they wanted to know about the nature of their illness. Those children whose age was from 6 - 11 years when they started ART were six times more likely to be disclosed to their counterparts (AOR
$=6.15[95 \% \mathrm{CI}=1.76,21.50])$. This study result showed that children's duration on ART was significantly associated with their HIV positive status disclosure; children who have taken ART for more than five years were 5.4 times more likely to be disclosed their HIV positive status than their counterparts $(\mathrm{AOR}=5.40[95 \% \mathrm{CI}=1.87,15.55])$. This could be explained that when children had been on ART for some period of time, they no longer experienced symptoms evident in their illness [7] and therefore they asked their caregivers subsequent questions about their HIV medications, and this results lack of adherence to treatment, and finally that leads into disclosure. In this study, children's HIV positive status disclosure was not associated with caregivers' sociodemographics (address and residence, occupation, marital status, relation with the child, HIV status), and schooling of the child, child's WHO clinical stages and diagnosis age.

The study had some limitations; caregiver reports of HIV status disclosure might have been affected by social desirability, and they might have said they disclosed when they hadn't truly disclosed. All information provided about children HIV diagnosis disclosure was from caregivers reports which could be biased and may not reflect the child's perceptions and may have resulted in recall bias, caregivers might not remember the child's age at diagnosis or duration on ART. This study was cross-sectional and could not establish the process and circumstances leading to disclosure, we recommend more studies be conducted to answer these questions. Lack of health care providers' perspectives was also another limitation. Furthermore, this study did not look at the family dynamics including the decision-making process in the family as there might be more other caregivers and/or family members who were involved in disclosing the diagnosis to children. Given this, further research involving qualitative methods could overcome this limitation.

\section{Conclusion}

This study revealed that the rate of disclosure of HIV positive status to HIV infected children was better (35.1\%) as compared to other similar settings. Caregivers' religion, children older than 10 years of age, family number, age when ART was started, and duration on ART were significantly associated with disclosure of HIV positive status to HIV infected children and were the independent determinant factors for disclosure of HIV positive status to HIV infected children in the multivariate analysis. Caregivers delayed disclosure because their child was too young to understand the HIV diagnosis and their child would not keep the diagnosis private (subjecting the child and the family to social rejection or that children would be exposed to isolation) and fear of negative reactions from the school and community. Disclosure was also delayed because caregivers believed that they lacked disclosure skills and relied on the support of the health care providers to disclose the HIV positive status to their children. These findings have implications for health care providers working in pediatric HIV services. It is important that addressing and scaling up efforts on stigma and discrimination in neighbourhood and communities settings and/or school levels. Establishing improved and focused counselling services for caregivers through professionally skilled counsellors so that caregivers could have a responsibility to decide on the proper time to disclose, and formation and strengthening of children's support groups will help children to know about HIV/AIDS and allow them discuss more about the barriers of disclosure. The findings of this study suggest more qualitative studies that may significantly affect HIV positive status disclosure to children; so that to develop guideline for disclosure of children with HIV/AIDS in Ethiopian context. 
Citation: Alemu A, Berhanu B, Emishaw S (2013) Challenges of Caregivers to Disclose their Children's HIV Positive Status Receiving Highly Active Anti Retroviral Therapy at Pediatric Anti Retroviral Therapy Clinics in Bahir Dar, North West Ethiopia. J AIDS Clin Res 4: 253. doi: 10.4172/21556113.1000253

Page 7 of 7

\section{Acknowledgment}

This research was funded by Addis Ababa University Grants for Graduate Research. Therefore, we are grateful to Addis Ababa University, College of Health Sciences for their financial support. We thank health care providers from all pediatric ART clinics of Bahir Dar for their facilitation during training of data collectors and data collection period. We would also like to thank all data collectors supervisor and research participants who took part in this study without whom this research would not have been realized.

\section{References}

1. UNAIDS (2012) Fact Sheet: The Global AIDS Epidemic.

2. Central Statistical Agency (2013) Ethiopia 2011 DHS. Stud Fam Plann 44: 233 242

3. Federal HIVIAIDS Prevention and Control Office (2012) Country Progress Report on HIVIAIDS Response.

4. FMOH (2006) Sixth Report, AIDS in Ethiopia

5. WHO (2011) Guideline on HIV disclosure counselling for children up to 12 years of age.

6. [No authors listed] (1999) Disclosure of illness status to children and adolescents with HIV infection. American Academy of Pediatrics Committee on Pediatrics AIDS. Pediatrics 103: 164-166.

7. Abadía-Barrero CE, Larusso MD (2006) The disclosure model versus a developmental illness experience model for children and adolescents living with HIVIAIDS in São Paulo, Brazil. AIDS Patient Care STDS 20: 36-43.

8. Biadgilign S, Deribew A, Amberbir A, Escudero HR, Deribe K (2011) Factors associated with HIVIAIDS diagnostic disclosure to HIV infected children receiving HAART: a multi-center study in Addis Ababa, Ethiopia. PLoS One 6: e17572.

9. Vaz LM, Maman S, Eng E, Barbarin OA, Tshikandu T, et al. (2011) Patterns of Disclosure of HIV Status to Infected Children in a Sub-Saharan African Setting. J Dev Behav Pediatr.

10. Wiener L, Mellins CA, Marhefka S, Battles HB (2007) Disclosure of an HIV diagnosis to children: history, current research, and future directions. J Dev Behav Pediatr 28: 155-166

11. Vaz LM, Eng E, Maman S, Tshikandu T, Behets F (2010) Telling children they have HIV: lessons learned from findings of a qualitative study in sub-Saharan Africa. AIDS Patient Care STDS 24: 247-256.

12. Abebe W, Teferra S (2012) Disclosure of diagnosis by parents and caregivers to children infected with HIV: prevalence associated factors and perceived barriers in Addis Ababa, Ethiopia. AIDS Care 24: 1097-1102.
13. Sphiwe Madiba (2012) Patterns of HIV Diagnosis Disclosure to Infected Children and Family Members: Data from a Paediatric Antiretroviral Program in South Africa. World Journal of AIDS 2: 212-221.

14. Kallem S, Renner L, Ghebremichael M, Paintsil E (2011) Prevalence and pattern of disclosure of HIV status in HIV-infected children in Ghana. AIDS Behav 15: 1121-1127.

15. Kimani-Murage EW, Manderson L, Norris SA, Kahn K (2013) "It's my secret": barriers to paediatric HIV treatment in a poor rural South African setting. AIDS Care 25: 744-747.

16. Moore AR, Williamson D (2011) Disclosure of Children's Positive Serostatus to Family and Nonfamily Members: Informal Caregivers in Togo, West Africa. AIDS Res Treat 2011: 595301.

17. Mahloko JM, Madiba S (2012) Disclosing HIV diagnosis to children in Odi district, South Africa: Reasons for disclosure and non-disclosure. Afr J Prm Health Care Fam Med 4: 1-7.

18. Tadesse AW, Berhane Tsehay Y, Girma Belaineh B, Alemu YB (2012) Behavioral and emotional problems among children aged $6-14$ years on highly active antiretroviral therapy in Addis Ababa: A cross-sectional study. AIDS Care 24: 1359-1367.

19. Wachira J, Middlestadt SE, Vreeman R, Braitstein P (2012) Factors underlying taking a child to HIV care: implications for reducing loss to follow-up among HIV-infected and -exposed children, SAHARA J 9: 20-29.

20. Nabukeera-Barungi N, Kalyesubula I, Kekitiinwa A, Byakika-Tusiime J, Musoke $P$ (2007) Adherence to antiretroviral therapy in children attending Mulago Hospital, Kampala. Ann Trop Paediatr 27: 123-131.

21. Ostrom RA, Serovich JM, Lim JY, Mason TL (2006) The role of stigma in reasons for HIV disclosure and non-disclosure to children. AIDS Care 18: 6065.

22. Kenya: Support Disclosure of HIV Status to Children (2010) Why Governments Should Promote Supportive Disclosure.

23. Hejoaka F (2009) Care and secrecy: being a mother of children living with HIV in Burkina Faso. Soc Sci Med 69: 869-876.

24. Demmer C (2011) Experiences of families caring for an HIV-infected child in KwaZulu-Natal, South Africa: an exploratory study. AIDS Care 23: 873-879.

25. Siu GE, Bakeera-Kitaka S, Kennedy CE, Dhabangi A, Kambugu A (2012) HIV serostatus disclosure and lived experiences of adolescents at the Transition Clinic of the Infectious Diseases Clinic in Kampala, Uganda: A qualitative study. AIDS Care 24: 606-611. 